\title{
Un vaso de Terra Sigillata Hispánica Tardía con decoración singular procedente de la Villa romana de Saelices El Chico (Salamanca, España)
}

\section{A bowl of Late Hispanic Terra Sigillata with an exceptional decoration, from the site of Saelices El Chico (Salamanca, Spain)}

\author{
Sarah Dahi Elena \\ Arqueóloga \\ M. ${ }^{a}$ Concepción Martín Chamoso \\ Arqueóloga
}

\begin{abstract}
RESUMEN
Se presenta un vaso de terra sigillata hispánica tardía de la forma Drag. 37t procedente de la villa romana de Saelices el Chico (provincia de Salamanca). La pieza está fabricada a molde y destaca por tener una decoración de tipo animalístico esquemático. El contexto cerámico en el que apareció se data en una fecha no anterior al siglo vi d.C. Se trata probablemente de una de las últimas producciones de terra sigillata de la Península Ibérica.
\end{abstract}

\section{SUMMARY}

We present a Late Hispanic terra sigillata bowl Drag. 37t coming from the Roman villa of Saelices el Chico (province of Salamanca, Spain). The piece belongs to the mould type production and it is notable for having a schematic animalistic decoration. The ceramic context in which it appeared must be placed in a date not earlier than the sixth century A.D. It is probably one of the last productions of terra sigillata of the Iberian Peninsula.

PALABRAS CLAVES: Cerámica Romana, Antigüedad Tardía, Noroeste Peninsular Hispano.

KEY WORDS: Roman Pottery, Late Antiquity, North-west of Spain.

\section{INTRODUCCIÓN}

La cronología final de la terra sigillata hispánica tardía fabricada a molde ha dado lugar a un importante debate todavía abierto. Esto se debe, en gran medida, a la escasez de contextos completos y bien datados que permitan ajustar dicha cronología, pero especialmente a la posible pervivencia de este tipo de piezas en contextos de cronología muy posterior a las de las fechas últimas de su fabricación (López Rodríguez 1985; Paz Peralta 1991; 2008; Buxeda y Tuset 1995; Juan Tovar 1997, 2010: 10, 12). La pieza que aquí presentamos aporta nuevos datos a la discusión, ya que cuenta con una decoración muy diferente a la habitual para este tipo de vasos, que podría estar marcando las fases finales de la producción de terra sigillata hispánica tardía.

Se trata de un cuenco Drag. 37t a molde con unas representaciones animalísticas esquemáticas. Procede del yacimiento de Saelices el Chico (provincia de Salamanca), concretamente de los materiales encontrados a lo largo de la campaña de excavación del 2005-2006. Estos materiales han sido tratados como parte de un estudio más completo que ha incluido varios contextos cerámicos de los siglos IV a viII en la provincia de Salamanca (Dahí 2010, 2012). El análisis de los contextos cerámicos de las U.E. excavadas en dicha campaña en la villa de Saelices el Chico ha permitido detectar, en todo el yacimiento, una secuencia de ocupación subsidiaria posterior al abandono de la villa como residencia aristocrática. Los contextos cerámicos estudiados acreditan una ocupación campesina del solar de la villa al menos desde inicios del siglo vi, aunque la secuencia de abandono podría llegar a alcanzar los primeros años del siglo vIII, a juzgar por algunas piezas con formas que recuerdan a ejemplares de los siglos VIII y IX. 


\section{LA VILLA ROMANA DE SAELICES EL CHICO}

La villa romana de Saelices el Chico (4040'16"$\left.6^{\circ} 37^{\prime} 56^{\prime \prime}\right)$ se localiza en el casco urbano del municipio del mismo nombre, a $99 \mathrm{~km}$. al suroeste de Salamanca y a unos $11 \mathrm{~km}$. al noroeste de Ciudad Rodrigo, sobre una cota media de 656 m. (Fig. 1).

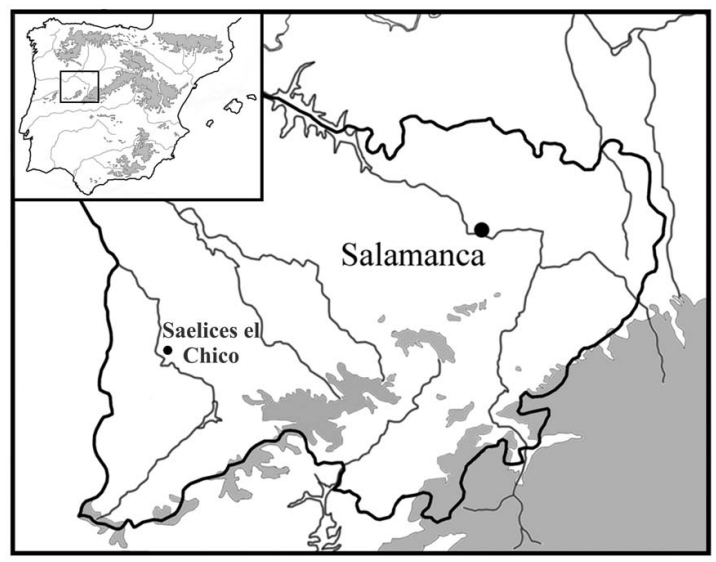

Figura 1. Mapa de la provincia de Salamanca con la localización de la villa romana de Saelices el Chico.

El yacimiento se conoce desde que en 1980, durante la construcción de los cimientos de una casa, aparecieron unos restos de fuste y basas de columna. Posteriormente se detectaron los restos de un mosaico y de lo que parecía ser una pared estucada, además de abundante cerámica y tegulae. En 1994 el ayuntamiento decidió llevar a cabo una primera campaña de excavación y prospección (Martín Chamoso y Hernández Hernández 1997a; 1997b; Pérez O1medo et alii 1997; Regueras y Pérez Olmedo 1997: 61-65). Los trabajos de excavación no se retomaron hasta 2005 (Martín Chamoso 2007), continuando durante los años 2008-2009.

Las excavaciones practicadas han puesto al descubierto una gran villa tardía de peristilo, exhumada solo de forma parcial, con habitaciones nobles pavimentadas con opus signinum y mosaicos (Cata 19). De entre ellas destaca una gran habitación con un mosaico que reproduce el mito de Belerofonte y la Quimera, probablemente un triclinio (Regueras y Pérez Olmedo 1997: 61-65). Se ha identificado también una estructura de planta semicircular, con una fachada en la que alternaban nichos de planta semicircular y cuadrada. Posiblemente se trata de un ninfeo perteneciente a la fase final de la villa, el cual amortiza un espacio termal de un momento anterior,

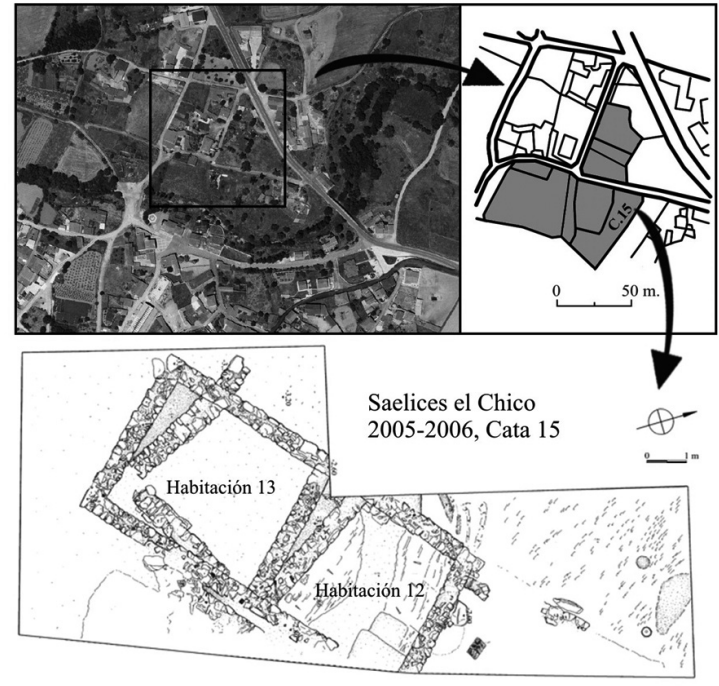

Figura 2. Plano del área total excavada y estructuras de la Cata 15 del yacimiento de Saelices el Chico.

inutilizado al experimentar la villa una gran reforma en el siglo IV. Al este del conjunto formado por las termas y el ninfeo aparecieron unas estructuras de habitación modestas (Cata 15), de donde procede la pieza que aquí tratamos (Fig. 2).

Las estructuras de la Cata 15 corresponden a un edifico con dos secuencias constructivas, que no forma parte del conjunto residencial de la villa, edificado con mampuesto de granito y lajas de pizarra trabados con barro. El conjunto está formado por una habitación de planta rectangular (Edificio 2), dividida en dos partes prácticamente simétricas por un muro construido en una fase posterior. Esta estructura, de la que solo se conservan los cimientos, amortizaba una estancia cuadrada anterior con una orientación ligeramente diferente (Edificio 1). Ambos edificios deben ser de nueva creación en época germánica y, aunque no es posible determinar el lapso de tiempo que media entre las dos secuencias constructivas detectadas, parecen prácticamente contemporáneas a juzgar por la técnica constructiva, que es la misma en las dos fases (Fig. 3).

En cuanto a la secuencia de los depósitos de esta Cata 15, aunque se han individualizado las U.E. tal y como exige la metodología de excavación, dado que no presentan contacto entre sí, es posible establecer una primera fase formada por paquetes sedimentarios (U.E. 12, 13, 14 y 15), posiblemente relacionada con la construcción del edificio y una segunda fase que se le superpone, de abandono y derrumbe de la edificación (U.E. 2, 3, 4, 5, 6, 7, 8, 9, 10 y 11), en la que se apreciaban lajas de pizarra, fragmentos de 


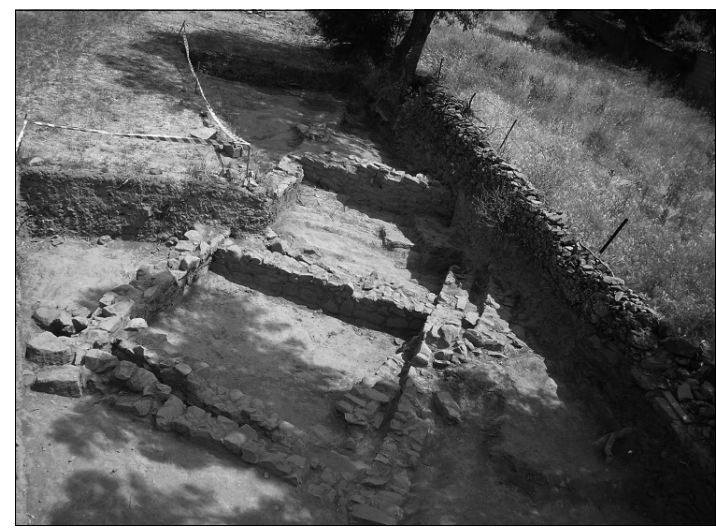

Figura 3. Fotografía de las estructuras excavadas en la Cata 15 de Saelices el Chico.

granito y ocasionales terracotas arquitectónicas en posición de caída.

\section{LA U.E. 5 DE LA CATA 15}

El contexto de la U.E. 5 de la Cata 15, un nivel de abandono y derrumbe, contaba con un gran número de restos cerámicos (1.080 fragmentos), entre los cuales se incluye un número significativo de fragmentos pertenecientes a familias cerámicas de cronología altoimperial, aunque el contexto está claramente dominado por producciones características del periodo bajoimperial y de época visigoda.

Aparte del material cerámico, que es la base para establecer las dataciones, hay que referirse al hallazgo de dos monedas, un antoniniano de Galieno acuñado en Roma, que en el anverso presenta el busto barbado del emperador con corona radiada y mirando a la derecha, acompañado de la leyenda [GALIEN]VS AVGVSTVS, y en el reverso una cabra estante hacia la izquierda con la leyenda [I]OVI CO[NS AV]G y la marca secundaria Ó (RIC V-I, 207 p. 149). La otra es también un antoniniano, pero de Aureliano para divo Claudio, de la ceca de Mediolanum. En el anverso aparece el busto barbado del emperador con corona radiada y manto, con la leyenda [D]IVO [CLAVDIO]. En el reverso un altar flaminar con la leyenda [C]ONSE[CRATIO] (RIC V-I, 261, p. 233). Ambas monedas proporcionan una data post quem que apenas tiene interés para datar el nivel, ya que como veremos, el conjunto cerámico apunta a fechas muy posteriores a la acuñación.

La U.E. 5 de la Cata 15 proporcionó igualmente otros materiales aunque no relevantes para la datación, entre ellos 11 fragmentos de vidrio de pequeño tamaño y formas no identificables, una pesa de telar, una piedra de afilar, un molino de mano, dos agujas en hueso, varios fragmentos óseos, varios objetos metálicos en hierro y bronce, y restos de terracotas arquitectónicas.

\section{EL CONTEXTO CERÁMICO DE LA U.E. 5 DE LA CATA 15. UN MARCO CRONOLÓGICO PARA LA DRAG. 37T A MOLDE CON REPRESENTACIONES ESQUEMÁTICAS ANIMALÍSTICAS}

El número total de fragmentos cerámicos recuperados asciende a 1.080, divididos en 13 familias cerámicas (Fig. 4).

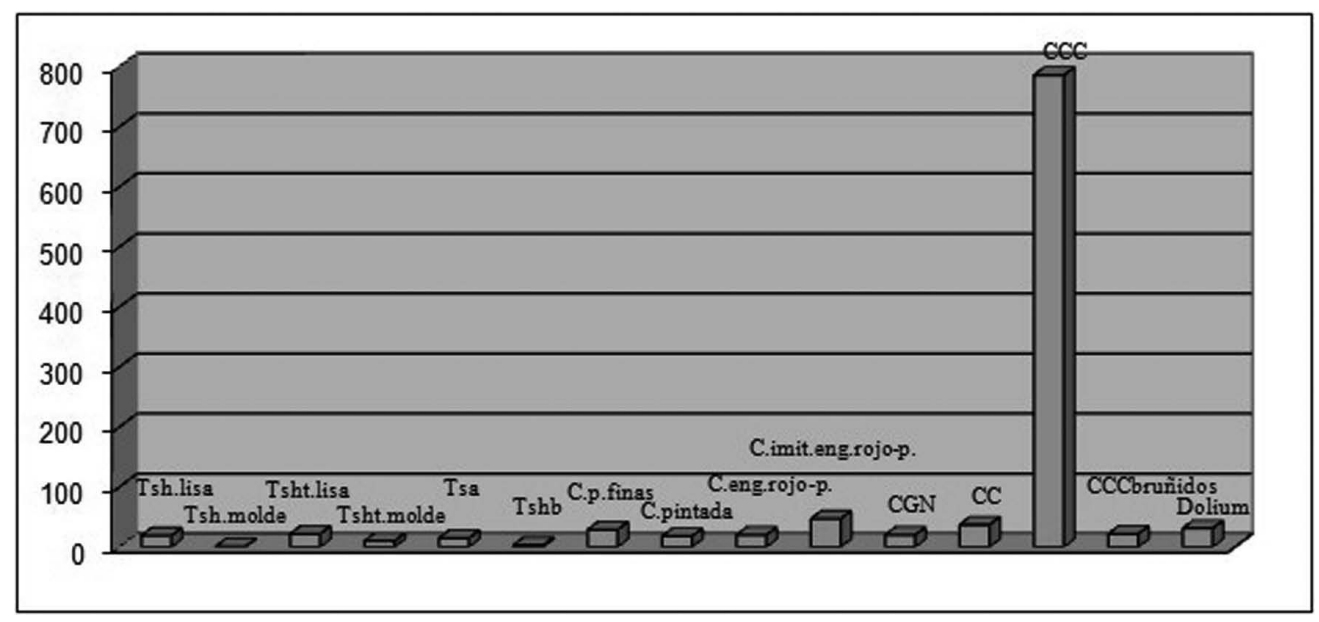

Figura 4. Gráfico de los materiales cerámicos de la U.E. 5 de la Cata 15 del yacimiento de Saelices el Chico. 
Dentro de éstas el grupo más numeroso pertenece al de las cerámicas comunes de cocina, con 786 fragmentos que suponen el $72,78 \%$ del total. En esta familia se han identificado gran cantidad de materiales residuales de época romana, pero cuenta también con algunas piezas cuyas formas remiten a cerámicas del siglo VIII y IX. Existe un número significativo de ollas con perfil en " $S$ " que aunque aparecen en los contextos más tardíos, podrían remontarse al pleno periodo romano. Junto a ellas hay otras piezas que indudablemente parecen más modernas, como las ollas de borde exvasado o vuelto sencillo y los cuencos carenados, siendo estas últimas piezas características de los contextos posteriores al siglo $\mathrm{v}$ y estando presentes incluso en depósitos fechados en el siglo VIII (Larrén et alii 2003: 278-279, 294-295, Fig. 3.1; Vigil-Escalera 2003: 378, Fig. 1).

La presencia de 22 fragmentos de cerámica común de cocina con líneas o retículas bruñidas indica fechas para el contexto no anteriores al siglo VI. Esta cronología está respaldada por una datación radiocarbónica en las U.E. 8 y 9 de la Cata 19 del mismo yacimiento de Saelices el Chico $(1530 \pm 35$ BP, UBAR-895, datación calibrada AD 430-603 - probabilidad del 95,4 \%-, AD 532-585 -probabilidad del 41,5\%) (Ariño y Dahí 2008: 272-273; Ariño y Dahí e.p.). En este mismo sentido hay que prestar atención a los acabados y a las decoraciones de la cerámica común de cocina. La presencia de incisiones y acanaladuras es un rasgo característico de los contextos del periodo visigodo avanzado, con cronologías en torno a los siglos VI y VIII (Larrén et alii 2003: 292; Alba y Feijoo 2003: 292; Azkárate et alii 2003: 359-369).

Entre las cerámicas comunes de cocina contamos también con algunos ejemplares que podrían datarse incluso en una fecha posterior. Concretamente se documentan cazuelas o barreños de borde exvasado o vuelto sencillo, con labio de sección almendrada, cuyos paralelos aparecen en contextos de finales del siglo v-mediados del vII (Larrén 2003: 301 y 303; Vigil-Escalera 2006: 707, Fig. 3), aunque alguna pieza cuenta con paralelos en contextos datados incluso en el siglo IX (Alba y Gutiérrez Lloret 2008: 595, Fig. 7, 604, Fig. 11 y 605). Hay también un ejemplar casi completo de una jarra piriforme monoansada, muy similar a piezas halladas en la provincia de Madrid, fechadas hacia el siglo VII o incluso principios del VIII (Caballero et alii 2003: 240-242, 246 y 256, Fig. 17; Vigil-Escalera 2006: 708-709 y 711, Fig. 11). Esta jarra recuerda también a una pieza de Mérida de la serie jarra/cántaro, que Alba y Gutiérrez Lloret incluyen dentro de su Horizonte III, emiral pleno, fe- chado en el siglo Ix (Alba y Gutiérrez Lloret 2008: 588-589, 595 Fig. 7, 596, 602, 603 Fig. 10-6 у 8). Apareció, además, el cuello de una botella o cántaro con decoración de líneas bruñidas verticales, que cuenta con paralelos en contextos de época islámica (Alba y Gutiérrez Lloret 2008: 602), así como con una cazuela biansada semejante a otras piezas aparecidas en contextos de los siglos VIII-IX (Alba y Gutiérrez Lloret 2008).

El resto de familias cerámicas de esta U.E. 5 aparecen mucho menos representadas. La cerámica fina de mesa marca fechas que no pueden ser anteriores a finales del siglo Iv. Se han recuperado 32 fragmentos de terra sigillata hispánica tardía, de los cuales 10 están fabricados a molde. La única forma representada es la Drag. 37t, tanto en la producción a molde - un fragmento - como en la producción lisa - 5 ejemplares- La presencia de un plato Hayes 60 de terra sigillata africana constituye otro referente para establecer una fecha post quem entre el 320 y el 380 , aunque en Albintimilium esta forma solo apareció en contextos de finales del siglo Iv o inicios del v (Hayes 1972: 97, Fig. 15 y 100; Paz Peralta 1991: 189). Igualmente, la presencia de 20 fragmentos de cerámica gris/negra con acabado bruñido y/o alisado indica que no podemos llevar la fecha de este contexto antes de los primeros años del siglo v. Sin embargo, tanto la cerámica gris/negra con acabado bruñido y/ o alisado, como la terra sigillata hispánica tardía y africana son frecuentes en contextos de cronología muy posterior.

En definitiva, la cronología de la U.E. 5 de la Cata 15 no puede ser anterior al siglo vi. La datación del cierre del depósito es sin embargo mucho más difícil de establecer. La presencia de vasos con formas cuyos paralelos se encuentran en los siglos VIII y IX debe tomarse con precaución, ya que se trata de tipos muy poco específicos que podrían iniciar su existencia en secuencias algo anteriores. Por otra parte, su presencia en contextos que han sido datados en el siglo IX no es un argumento para excluir su existencia en momentos anteriores.

\section{EL CUENCO DRAG. 37T A MOLDE CON DECORACIÓN ANIMALÍSTICA}

La fecha final de la producción de la terra sigillata hispánica tardía ha generado intensos debates, ya que se trata de una cuestión clave, no solo para la datación de los contextos de transición entre el periodo romano y visigodo, sino también porque esta producción es la última superviviente de la cerámi- 
ca de tradición clásica fabricada en la península Ibérica, lo que la convierte en uno de los últimos trazos culturales de la tradición romana en un mundo que se extingue. Hasta ahora se ha sugerido como fecha final de la producción de terra sigillata hispánica tardía, una datación en torno a finales del siglo VI (López Rodríguez 1985: 117-118; Paz Peralta 1991: 230-231; 2008: 507). Tras nuestro estudio no podemos establecer una fecha de desaparición para esta producción con seguridad, pero sí podemos decir que la terra sigillata hispánica tardía se encuentra prácticamente ausente de los contextos que hemos fechado en torno al siglo vi (Ariño y Dahí e.p.).

Con todo, debemos tener en cuenta la posibilidad de una cierta pervivencia hasta fechas más o menos avanzadas, a juzgar por la presencia de piezas bastante singulares en lo que a su repertorio decorativo respecta. El caso aquí presentado es uno de los más significativos y enigmáticos. Se trata de un cuenco Drag. 37t realizado a molde en el que se aprecia una iconografía animalística esquemática completamente insólita, ya que no pertenece al repertorio clásico de esta producción cerámica. La pasta es muy fina y de color amarillo (Munsell yellowish red 5YR 5/8). Ambas superficies son de color rojo (Munsell red 2.5YR 4/6) y conservan escasos restos de engobe, ya que se encuentran muy desgastadas (Fig. 5).

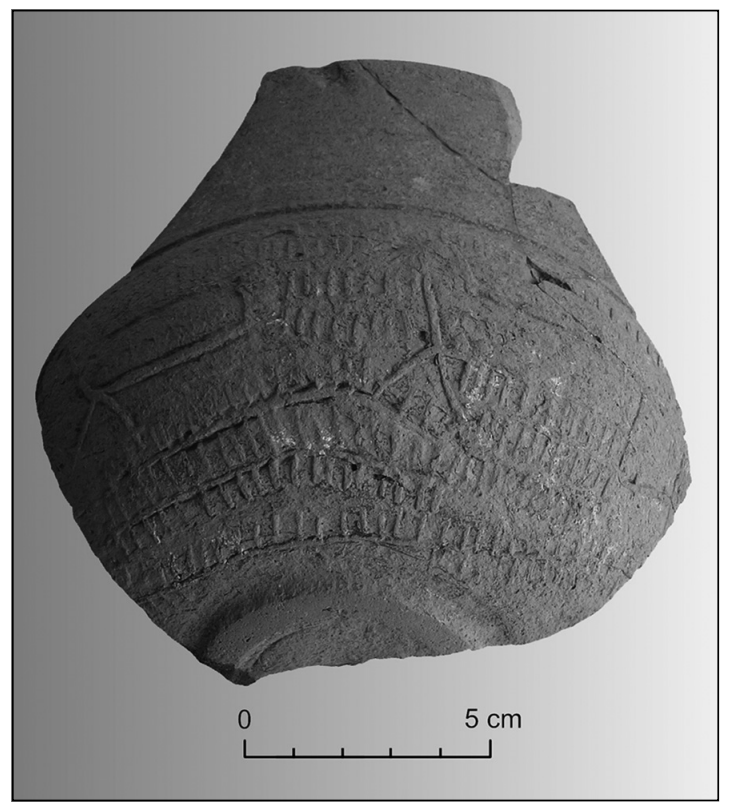

Figura 5. Fotografía del cuenco de terra sigillata hispánica tardía a molde Drag. 37t. con decoración animalística esquemática, de la U.E. 5 de la Cata 15 de la villa romana de Saelices el Chico.

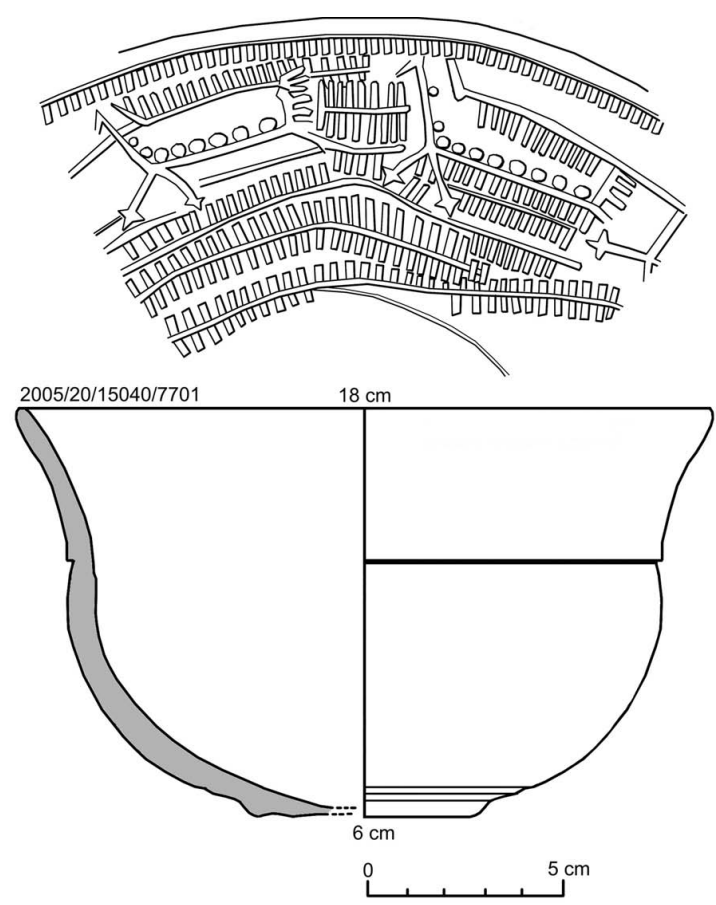

Figura 6. Dibujo del cuenco de terra sigillata hispánica tardía a molde Drag. 37t. con decoración animalística esquemática, de la U.E. 5 de la Cata 15 de la villa romana de Saelices el Chico.

La decoración a molde ocupa toda la parte central e inferior de la pieza y, a pesar de que ha sufrido un cierto deterioro, pueden apreciarse claramente dos figuras consecutivas de perfil alargado, estilizadas, que destacan ligeramente del resto de relieves, apareciendo rodeadas de cenefas o bandas rayadas que sirven de base a las figuras o rellenando el fondo. Ambas figuras pueden interpretarse como una representación animalística esquematizada. Las imágenes, prácticamente idénticas, presentan un largo cuerpo con un fino cuello y una cabeza esquemática. Bajo el cuerpo y a la altura del cuello, se distinguen dos patas terminadas en tres dedos. La figura más a la izquierda termina en lo que podría ser una cola y dos patas traseras que se desdibujan. La otra figura, situada a la derecha, únicamente conserva la parte delantera con una de sus patas arqueada hacia atrás. No hemos hallado paralelos para estos motivos figurados, manteniéndose su interpretación, por el momento, abierta, ya que las alternativas sobre su significado pueden ser muy diversas (Fig. 6).

Al ser las figuras tan esquemáticas resulta complicado determinar cual podría ser la especie animal representada. Su forma es tan poco precisa que ni el hecho de mostrar tres dedos es suficientemente signi- 
ficativo como para pensar que se trata de garras en vez de pezuñas. Tampoco resulta sencillo darle un significado a las bandas rayadas que enmarcan las figuras. Probablemente esta decoración es sencillamente fruto del horror vacui del artista sue fabricó la pieza. A pesar de ello, tampoco podemos descartar que se trate de una representación igualmente esquematizada del entorno en el que se encuentran las figuras, tal vez una colina o un cercado. Lo abstracto de la imagen abre la posibilidad incluso de que se trate de algún objeto con rasgos zoomorfos. Entre ellos pueden barajarse diversas opciones, siendo posible incluso que estemos ante una escena naval representada por las naves con sus remos en el mar o varadas y apoyadas sobre vigas. En cualquier caso, mientras no contemos con más información sobre la pieza, esto son solo conjeturas. Lo que sí puede afirmarse, es que se trata de un modelo decorativo que nada tiene que ver con la tradición romana clásica. La singularidad de la decoración hace difícil la búsqueda de paralelos dentro la terra sigillata hispánica tardía. Pese a ello resulta interesante observar las semejanzas decorativas que existen entre la pieza que aquí presentamos y las cerámicas de época merovingia decoradas a moulette, aparecidas en torno a la región parisina, procedentes de necrópolis y fondos de cabaña (Legoux 1992: 112; 2006: 325). Esta producción es diferente en su técnica de fabricación y en su forma a la terra sigillata hispánica tardía, pero presenta decoraciones esquemáticas de tipo animalístico — cánidos en su mayoría — muy similares a nuestra pieza. Según René Legoux estas cerámicas, que data desde finales del siglo V-hasta mediados del siglo VII (Legoux 1992: 142; 2006: 325), tienen un claro origen simbólico cristiano que las relaciona con la sigillata tardía decorada de Argonne de mediados del siglo v-principios del vi (Legoux 1992: 114, 128; 2006: 328).

Al contar únicamente con un fragmento y no con la pieza completa, tampoco es posible determinar si la imagen pertenece a una escena estática o reproduce un suceso secuenciado, similar a los que aparecen en las denominadas de estilo narrativo por Juan Tovar, hasta ahora desconocido y presente en piezas de las últimas producciones de terra sigillata hispánica tardía fabricada a molde, como la Drag. 37t a molde del yacimiento de El Camino de Sta. Juana $(\mathrm{Cu}-$ bas de la Sagrada, Madrid) que apareció formando parte de un contexto fechado a principios del siglo v (Juan Tovar et alii e.p.). Según esto, la pieza de Saelices el Chico es por el momento un unicum que forma parte del repertorio de piezas de terra sigillata hispánica tardía que podrían estar marcando el final de esta producción cerámica en torno al siglo VI.
Para concluir, es interesante señalar también la escasa variedad que presenta el repertorio formal de la terra sigillata hispánica tardía en nuestra zona de estudio, repertorio que está prácticamente limitado a las formas Ritt.8 y, especialmente, Drag. 37t. Esto obliga a considerar la relevancia que pueda tener, a la hora de determinar la fecha final de la terra sigillata hispánica tardía, la aparición, en los registros estratigráficos de la zona, de una cerámica que adopta habitualmente la forma del cuenco Ritt.8 aunque está fabricada con una pasta y una técnica que nada tiene que ver con la de la terra sigillata hispánica tardía, con barnices que recuerdan a los típicos de engobe rojo-pompeyano. Estas piezas se fechan, a grandes rasgos, entre finales del siglo vi y los primeros años del siglo VIII (Ariño y Dahí e.p.) y están representadas en la U.E. 5 de la Cata 15 de Saelices el Chico por 47 fragmentos. La aparición de esta producción en este periodo podría ser otro indicio a valorar a la hora de fechar el final de la producción de terra sigillata hispánica tardía hacia finales del siglo vi, siendo probable que en torno a esa fecha los alfareros desconocieran ya la técnica de fabricación de la terra sigillata hispánica tardía, viéndose obligados a fabricar estos cuencos con una metodología que nada tenía que ver con la de la producción que le dio su origen.

\section{BIBLIOGRAFÍA}

Alba, M. y Feijoo, S. 2003: "Pautas evolutivas de la cerámica común de Mérida en épocas visigoda y emiral", L. Caballero, P. Mateos y M. Retuerce (eds.), Cerámicas tardorromanas y altomedievales en la Península Ibérica. Ruptura y continuidad, Anejos Archivo Español Arqueología XXVIII, Madrid, 483-504.

Alba, M. y Gutiérrez Lloret, S. 2008: "Las producciones de transición al Mundo Islámico: el problema de la cerámica paleoandalusí (siglos viII y IX)", D. Bernal Casasola y A. Ribera Lacomba (eds.), Cerámicas hispanorromanas. Un estado de la cuestión, Cádiz, 585-613.

Ariño, E. y Dahí, S. 2008: “Contextos cerámicos de la Antigüedad Tardía y la Alta Edad Media en la provincia de Salamanca (España)", SFECAG, Actes du Congrès de l'Escala-Empúries, Marsei1le, 265-276.

Ariño, E. y Dahí, S. e. p.: "Ceramic contexts from Late Antiquity to the Early Middle Ages (350700 c) in rural settlements of Salamanca (Spain)", LRCW 4. Late Roman Coarse Wares, Cooking 
Wares and Amphorae in the Mediterranean: Archaeology and Archaeometry, British Archaeological Reports International Series 1340, Oxford.

Azkárate, A., Núnez, J. y Solaun, J. L. 2003: "Materiales y contextos cerámicos de los siglos vi al x en el País Vasco", L. Caballero, P. Mateos y M. Retuerce (eds.), Cerámicas tardorromanas y altomedievales en la Península Ibérica. Ruptura y continuidad), Anejos Archivo Español Arqueología XXVIII, Madrid, 321-370.

Buxeda, J. y Tuset, F. 1995: "Revisió crítica de les bases cronològiques de la terra sigillata hispánica", Pyrenae 26, 171-188.

Caballero, L., Retuerce, M. y Sáez, F. 2003: “Las cerámicas del primer momento de Santa María de Melque (Toledo), construcción, uso y destrucción. Comparación de Santa Lucía del Trampal y El Gatillo (Cáceres)", L. Caballero, P. Mateos y M. Retuerce (eds.), Cerámicas tardorromanas y altomedievales en la Península Ibérica. Ruptura y continuidad, Anejos Archivo Español Arqueología XXVIII, Madrid, 225-271.

Dahí, S. 2010: Contextos cerámicos de la Antigüedad Tardía y Alta Edad Media (siglos IV-VIII) en los asentamientos rurales de la Lusitania septentrional (Provincia de Salamanca), Tesis Doctoral Inédita, bajo la dirección del Dr. Enrique Ariño Gil, Universidad de Salamanca, Salamanca.

Dahí, S. e. p.: Contextos cerámicos de la Antigüedad Tardía y Alta Edad Media (siglos IV-VIII d.C.) en los asentamientos rurales de la Lusitania septentrional (Provincia de Salamanca), British Archaeological Reports International Series 2401, Oxford.

Hayes, J. W. 1972: Late Roman Pottery, London.

Juan Tovar, L. C. 1997: "Las industrias cerámicas hispanas en el Bajo Imperio. Hacia una sistematización de la sigillata hispánica tardía”, R. Teja y C. Pérez González (eds.), La Hispania de Teodosio. Congreso Internacional 2, Valladolid-Segovia, 543-568.

Juan Tovar, L. C. 2010: Mesa Redonda: La Terra Sigillata Hispánica Tardía y sus contextos:estado de la cuestión. Resumen y Conclusiones, Boletín Ex Officina Hispania n², 10-29.

(http://www.exofficinahispana.org/publicaciones/ Boletin\%20SECAH10\%2002\%20(web). pdf (acceso 10-06-2011)

Juan Tovar, L. C., Sanguino Vázquez, J. y Oñate Baztán, P. e. p.: "Un conjunto tardorromano excepcional en Cubas de la Sagra (Madrid): I. La cerámica”, D. Bernal, L. C. Juan, M. Bustaman- te, J. J. Díaz y A. M. Sáez (eds.), I Congreso Internacional de la SECAH: Hornos, talleres y focos de producción alfarera en Hispania, Cádiz (en prensa).

Larrén, H., Blanco, J. F., Villanueva, O., Caballero, J., Domínguez, A., Nuño, J., Sanz, F. J., Marcos, G. J., Martín, M. A. y Misiego, J. 2003: "Ensayo de sistematización de la cerámica tardoantigua en la Cuenca del Duero", L. Caballero, P. Mateos y M. Retuerce (eds.), Cerámicas tardorromanas y altomedievales en la Península Ibérica. Ruptura y continuidad, Anejos Archivo Español Arqueología XXVIII, Madrid, 273-306.

Legoux, R. 1992 : “L'art animalier et la symbolique d'origine chrétienne dans les décors de céramiques $\mathrm{du} \mathrm{VI}^{\mathrm{e}}$ siècle après J.C. au nord du Bassin parisien”, Revue archèologique de Picardie 12, 111142.

Legoux, R. 2006: "Diffusion en Île-de-France et en Picardie de la céramique ornée entre la fin du v et le vir siècle", V. Hincker y P. Husi (coords.) : La céramique du Haut Moyen Âge dans le nordouest de l'Europe v - x siècles. Actes du colloque de Caen, 2004. Bilan et perspectives dix ans après le colloque d'Outreau, Condé-sur-Noireau, 325336.

López Rodríguez, J. R. 1985: Terra sigillata hispánica tardía decorada a molde de la Península Ibérica, Salamanca.

Martín Chamoso, C. 2007: Memoria técnica de excavación. Villa romana de Sahelices el Chico, Salamanca (informe inédito, Biblioteca del $\mathrm{Mu}-$ seo de Salamanca).

Martín Chamoso, C. y Hernández Hernández, A. B. 1997a: "La villa romana de Sahelices el Chico", Revista de Arqueología 191, 50-53.

Martín Chamoso, C. y Hernández Hernández, A. B. 1997b: Informe técnico de la excavación arqueológica de la villa romana de Sahelices el Chico, Salamanca (informe inédito, Biblioteca del $\mathrm{Mu}-$ seo de Salamanca).

Paz Peralta, J. Á. 1991: Cerámica de mesa romana de los siglos III al VI d. C. en la provincia de Zaragoza. (Terra sigillata hispánica tardía, african red slip ware, sigillata gálica tardía y phocaean red slip ware), Zaragoza.

Paz Peralta, J. Á. 2008: "Las producciones de terra sigillata hispánica tardía", D. Bernal y A. Ribera i Lacomba (eds.), Cerámicas hispanorromanas. Un estado de la cuestión, Cádiz, 497-539.

Pérez Olmedo, E., Regueras, F., Martín Chamoso, C. y Hernández Hernández, A. B. 1997: “Arquitectura romana tardía en la provincia de Salamanca: 
el complejo de Sahelices el Chico", Boletín del Seminario de Estudios de Arte y Arqueología 63, 179-201.

Regueras, F. y Pérez Olmedo, E. 1997: Mosaicos romanos de la provincia de Salamanca, Arqueología en Castilla y León. Monografías 2, Valladolid. RIC, V-I = Webb, P. H. 1972 (1 ${ }^{\mathrm{a}}$ ed. 1927): The Roman Imperial Coinage Vol. V-Parte I-Valerian to Florian, London.

Vigil-Escalera, A. 2003: "Cerámicas tardorromanas y altomedievales de Madrid", L. Caballero, P. Mateos y M. Retuerce (eds.), Cerámicas tardorromanas y altomedievales en la Península Ibérica. Ruptura y continuidad, Anejos Archivo Español Arqueología XXVIII, Madrid, 371-387.

Vigil-Escalera, A. 2006: "La cerámica del periodo visigodo en Madrid”, J. Morín de Pablos (ed.), La Investigación Arqueológica de la Época Visigoda en la Comunidad de Madrid, Zona arqueológica 8 (3), 705- 713.

Recibido: 19-09-2011

Aceptado: 11-01-2012 